\title{
Effective Application of Information System for Purchase Process Opti- mization
}

Pearl Keitemoge* Daniel Tetteh Narh

School of Engineering Management, Beihang University, Beijing, 100191, China

A R T I C L E I N F O
Article history:
Received: 09 August, 2020
Accepted: 10 October, 2020
Online: 20 November, 2020
Keywords:
purchasing management
information technology
supply chain ERP System
Cloud-based
Purchase Process Optimization
Internet

\section{Introduction}

Technology is evolving rapidly and purchasing products are ongoing around companies/industries, therefore it is key that supply management is enhanced to develop business around the globe with and through the help of Information System (IS). Information Technology (IT) systems have exponentially increased and enhanced marketing technique and purchasing process for buyers (companies and individuals) and seller of products. Users of knowledge systems have progressively found themselves as customers of multiple technology vendors, this IT procurement method assumes bigger and vital management. In light of the upward trend of technology, IT system has or will become must-have for every company that is planning intending to compete for customers, this because we are in an era in which customers are constantly demanding fast service from service providers. Therefore, for companies to thrive in this ever growing technology age, they must change with rhythm to meet user demand.

In recent years, the world's economy at large has become increasingly competitive. It has practically become an ineffective and unsustainable approach for firms to sustain the upward com-

\footnotetext{
*Corresponding Author: Pearl Keitemoge, \& Email: pkeitemoge@gmail.com
}

petitiveness in the market and further returning profits margins for investors through a frequent increase in product cost. Instead, firms must integrate and harness the premise of product innovation to achieve and deliverer higher quality, and quicker response times or performance, while continually maintaining the minimum unit cost [1,2].

Suppliers are very crucial in making firms competitive, by providing firms with products that meet user demands [1]. The impact of integrating IT in purchasing process or supply management has a great influence on every firm's competitive ability. In [3], a piece empirical information was collected from a total of 108 Taiwanese firms was studied and interviews with four active managers were carried to collect the sensible insights of the theoretical framework of e-procurement and provide chain performance.

According to [3-5], information sharing and supply chain integration allow a strategic viewpoint when implementing eprocurement systems intended to improve supply chain performance. This project will be sharing new ideas on how a new technology channel is making a difference in purchasing and supply management. Therefore, more discussion and discoveries will be made in relation to the information system in place used for purchasing 
process currently. It is with the new technologies that new strategies are emerged to impact both organization and individuals on their ways of purchasing and supply of goods. The business can simply grow spontaneously from their lowest profits to a higher one with the aid of the information technology systems in place.

\subsection{Purchasing Process}

Entails the stages that any organization or business that want to obtain services and goods for the productivity of the business defined as the purchasing process. The author in [6] concisely explained procurement practices as principal activities designed and undertaken by an organization to aid promote and facilitate effective management across the organization's supply chain.

The stage differs based on the specific need of every business or organization. The process becomes completed after specifications have been developed, a buying team monitored and cooperating with the supply manager will select suppliers, generate the request for proposals, evaluate the proposals and select a supplier based on established selection criteria [1,7].

It is therefore extremely important that all necessary supply chain information should be readily available to all companies involved, and the business process should be structured in a way that allows the full access to the available information. This information will be utilized in the purchasing process. There main aim of every firm is to maximize profit and minimize loss, therefore procurement performance very important dependent on many factors as indicated in [8.9] by Figure 1 Assessment of procurement performance helps organizations to reduce cost, enhance profitability, assured supplies, quality improvements and competitive advantage [6]

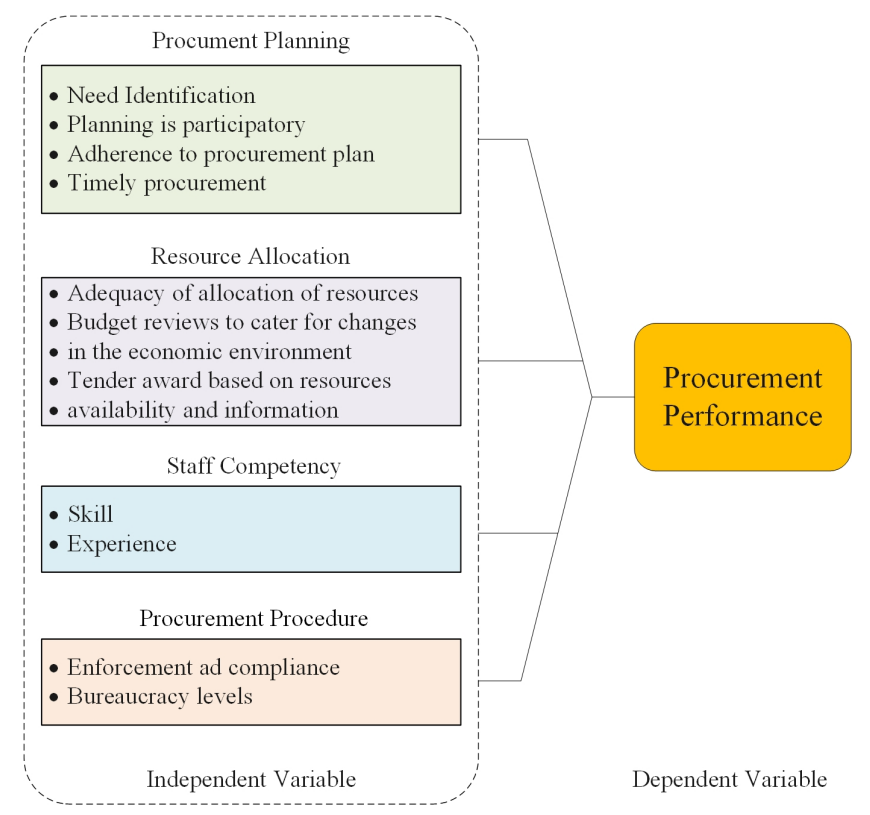

Figure 1: Framework for Procurement Performance 9

Figure 1 shows and indicates that procurement performance is very sophisticated and it linked to many other parameters such as procurement planning, resource allocation, staff competency, and procurement procedure.
The practice-based commentary outlined both cases of success and failure of firms in relation to the implementation of IS in the purchase process. In light of success, Wal-Mart adopted the implementation of IS in some sections of purchase process, namely, materials management, product ordering, and inventory-tracking through Radio Frequency Identification (RFID Tag, this adoption enabled the firm to have real-time information in light of demand forecasting as a result of RFID based inventory management, this eventually lead effective inventory turnover and mitigated inventory costs. The firms' adoption IS applications have thus supported and made it possible for the company's cut cost on the purchase process.

Concerning failure, Nike invested $\$ 100$ million in the deployment of purchase process IS software but failed handle or prevent significant inventory shortages leading to larger unmet demand, this is due inadequate and inefficient planning for application integration with its existing supply chain objectives [10]. These examples clearly outline the importance of firm's purchase process managers to pay close attention in aligning information systems that are deployed in the purchase process system with the goals and objectives of the purchase process itself [11].

In this section, we examined in detail the Purchasing processes, which includes the product requirement, good delivery, payment, supply management, management of purchasing effectively, suppliers evaluation and selection, review specifications and the awarding of the purchase contracts.

\subsection{Purchasing types}

Purchasing is defined to be a company/organization or individual paying for goods or services in order to accomplish business or personal defined goals [12].

Personal: This is the system of individual buying products or services for their personal use. They do not engage any third party to negotiate the prices and make selections on the supplier.

Mercantile: The purchasing that is facilitated by the middleman. Retailers and wholesalers are found under this type. They arrange their own channel of distribution of products to their customers.

Industrial: This is the system of buying raw materials to later produce finished products. The materials and necessary tools needed to produce products are also purchased here.

Government or institutional: Buying in bulk for government departments and institutions. Governmental purchases have a high level of bureaucracy and decision making concerning the product.

Table 1: Economic Contribution and Dependency

\begin{tabular}{|c|l|l|}
\hline Purchasing type & $\begin{array}{l}\text { Contribution on the econ- } \\
\text { omy }\end{array}$ & $\begin{array}{l}\text { Level of dependency on } \\
\text { the economy }\end{array}$ \\
\hline Personal & Low contribution & Highly dependent \\
mercantile & Medium contribution & Low dependency \\
Industrial & High contribution & High Independent \\
Government & High Contribution & High independent \\
\hline
\end{tabular}

The Table 1 shows the contributions and how dependent each different purchasing types have on the economy of a country.

The Figure 2 shows the bureaucracy prism for all the abovementioned types of purchasing from bottom to top. The bureaucracy 
exists because of the complex leadership structure embedded in each type.

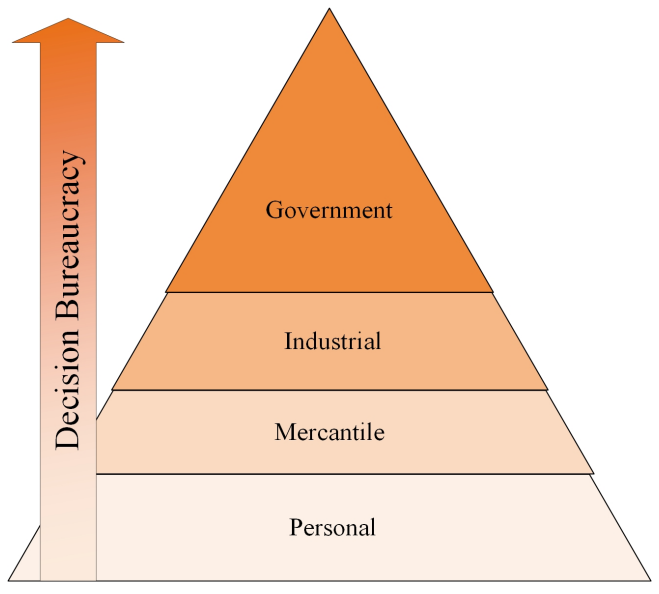

Figure 2: bureaucracy prism

Much of the procurement bureaucracy can actually be eliminated by the implementation of the information system and enhance effective firm data handling and management, especially simple decision which will directly increase productivity.

\section{Identifying the Process Involved in Pur- chasing}

Knowing the processes involved in purchase process is crucially important to establishing an effective and productive supply chain management across any firm. These are stages that defines the product requirement, product size, product safety, performance and necessary maintenance requirement, payment and delivery method and supplier selection strategy and requirement.

\subsection{Product Requirements (specification)}

Before defining or selecting product requirement, the business firm must identify the task product that they will be handling, usage environment, workload and lifespan of the product.Defining some of these parameters can be very daunting and almost impossible, task type can easily be specified but not future environmental conditions. Information technology is helpful in the defining of product specification, the future workload can be approximately specified or predicted using current machine learning algorithms such as neural network, multi-linear regression and other existing predictive analysis algorithms. Product requirement is vast includes functionality, computer application user interfaces, communications, reports, customer services, user help manuals \& self-help tutorials, service delivery staffing licensing/certifications Product requirement parameter can also vary according to the kind of product that is required. The basic but most important parameter are discussed as in Figure 3

A well-defined product requirement is very important. If these parameters are not defined properly it subsequently slows the product design and development phases by having to define and re-clarify objectives and requirements and this also increases production costs due to change requests caused by having to fix execution errors or omissions.

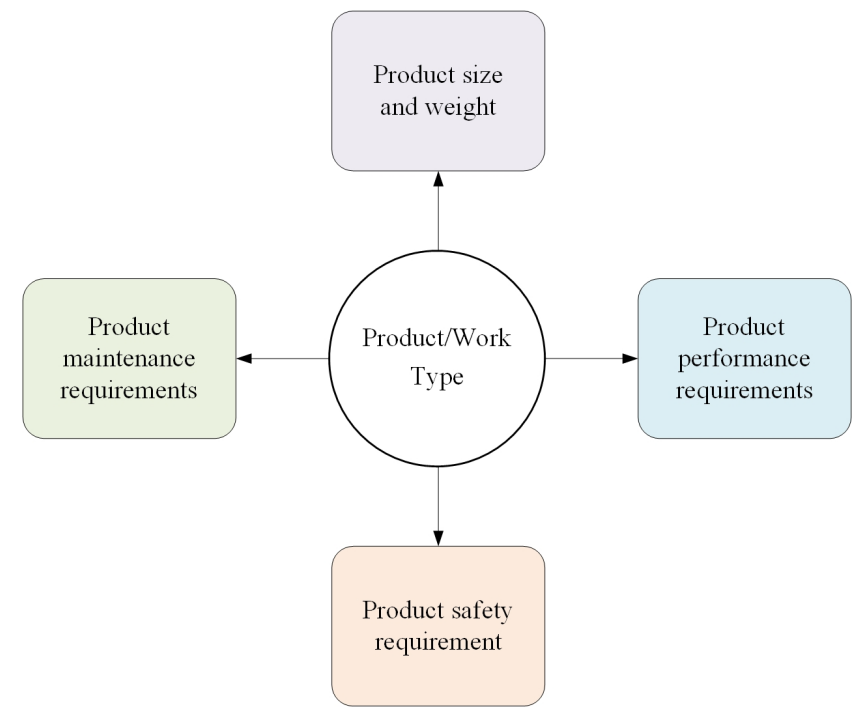

Figure 3: Basic Product Requirements

\subsubsection{Product size and weight}

The customer will provide the firm with the size of the product they need. In an organization size also is needed to add to the specification of the products.

\subsubsection{Product performance requirements}

The performance requirement provides the firm with operational details. How fast, often and slow the product will be when used. Other things to consider are the shelf life of the product, the power requirements, and the service life.

\subsubsection{Product safety requirement}

The safety requirements of a product are the potential sources of liability. Identifying these in the specification process enables suppliers to a provide possible solution to the sources such as potential operational hazards, manufacturing and assembly hazards. These hazards directly have an effect on the product life span.

\subsubsection{Product maintenance requirements}

This sort to find out if the product can be maintenance-free? If routine maintenance is required, can it be done by the owner/operator? Will professional maintenance be required?

Well defined product requirement is very important. If these parameters are not defined properly it subsequently slows the product design and development phases by having to define and re-clarify objectives and requirements and this also increases production costs due to change requests caused by having to fix execution errors or omissions. 
Technology is making the requirements available to the supply via the systems that are availed to the supply to aid the collection of information on the product. If companies employ and integrate information system into these phase of product procurement and facilities quick and fast exchange of this information between the suppliers and customers.

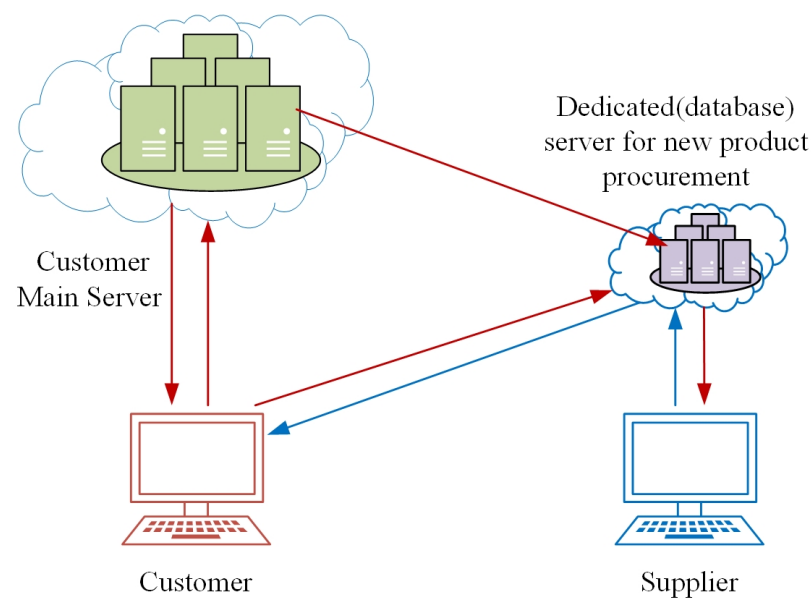

Figure 4: Product Requirement and Information System Workflow

Figure 4 shows a quick and simplified view of information flow when the information system is integrated into the procurement process. The customer can grant the supplier access to a dedicated database server for a specified project or product server. With this access, the supplier can have quick access to the product requirement information, the supplier can also give suggestion and comments (as indicated by the blue arrow) on the product quick before product manufacture commence. Any suggestion indicated by the supplier are reviewed by customer and if suggestions are viable, the changes are then updated to the main server and confirmed to the dedicated product databases server. Using the information system, process speeds up thus avoiding unnecessary delay in the procurement process of the product. The first aspect of purchasing is for the business to identify the product that they will need and provide a detailed specification.

The product or service type needed by any business entity can either originate from the manager's recommendation or collective customers demand. Technology is used in the stage by collecting the specifications of service or goods electronically and the information is later captured into a computer for processing and used in the next stage. Frequent communication between the customers and suppliers is done by the emails. The detailed specifications are compiled and captured into forms in the computer application programs for easier access by other key role players. Hence, improving communication and reduces the design complexities that add more cost to building cost specification [1, 13]. Sharing of information real-time is also crucial because the shrinking product lifestyle and the competitive advantage often reduces time to market [1 4 , 4.7$]$.

\subsection{Evaluation and Suppliers Selection}

In this purchasing process stage, the team supplier receives the proposals and prices and selection is made based on who is able to guarantee quality assurance and competitive price of the products. The team also review the product requirement specified by the suppliers to cross check with the stipulated need of the company and the individuals. A review of different requisitions may also reveal that different users actually require the same material [14]. By combining the purchase requirements, purchasing can often achieve a lower total cost. The team also evaluate the suppliers based on the capability of the supplier. Comparing the place of the distribution of the supplier, global versus regional and local.

The supplier selection factors considered by firms include but not confined to the supplies team size, the supplier public evaluation or rating, supply risk level, manufacturer versus distributor. Supplier evaluation can be a rigorously daunting task due parameters factors come to play, such as price competitiveness, ability to fulfill expected product delivery time, budget optimization. All procurement expert or manager must know the thorough or effective evaluation will result in the proper selection of suppliers. Making a decision requires a wide consideration of all possible alternatives and then choosing the appropriate and optimal supplier (OpS). According to [15.16] selection process considerably relies on both the subjective and objective judgment in different areas. The different areas include (1) inter-connected criteria definition: for both qualitative and quantitative (2) criteria conflict: leading to conflicting objectives of the criteria (3) involvement of several alternatives: due high competition (4) internal and external constraints: established and imposed on buying process [16].

In [17], through extensive review and professional interviews, the author established three key factors for supplier selection measure. He further proposed that underlying the documented suppliers criteria is the reason rate supplier effectiveness in terms of quality and repair capabilities and control alignment with the purchasing firm [17]. Another author in [18] also established an integrated model by merging the analytical hierarchy process and grey relation analysis for a single evaluation model. Unavailability of precisely needed or complete information intrinsically increases the difficulty of any decision making. Therefore, most experts in the procurement arena agree that there is no one-for-all confined strategy or method to perform evaluation and selection of suppliers, and organizations use several different approaches in order to obtain optimal selection [19] such as cost, maintenance, product life cycle as illustrated in [20.21].

Regardless of the selected approach, the overall objective of the evaluation process should aim to reduce know or perceive procurement risk and maximize overall value to the purchasing firm. ITT system can be utilized by purchasing firm to ease the supplier selection process and evaluation criteria that cannot be biased. Accessing all needed information from all the potential suppliers using the traditional method is not an easy task and this subsequently delays the supplier selection process. Information system integration aid fasts forward this stage of purchasing process instead of using the 
traditional method of scheduling and arranging several long hours in meetings with all potential before deciding whether the supplier meets firm's requirement or not.

\subsubsection{Effective Data Collection}

Firms that considerably invest and implements modern technology (information system) is at an added advantage of accessing all necessary information from all potential suppliers $(s 1, s 2 \ldots s N)$ data center as in Figure 4 .

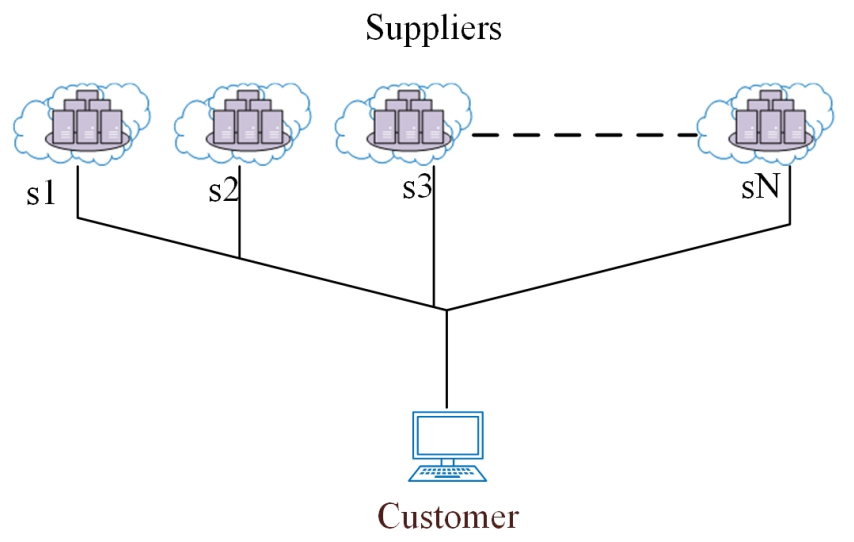

Figure 5: Firms/Customer Accessing Information from $N$ Suppliers

An Information System can virtually enable firms to collect and gather important supplier related data such as qualification information through internal and external questionnaires and self-service profiles, risk factor, and policy compliance to aid choose best suppliers. [T] also makes firms proactively more effective in achieving business alignment when planning and creating negotiation documents, it also helps create and alerts for monitoring the availability of new information that might affect and influence supplier management, capabilities, or risk factors. Suppliers, as well as sourcing teams, gain adequate and simultaneous real-time visibility of the information on transactions as well as current and upcoming sourcing activities.

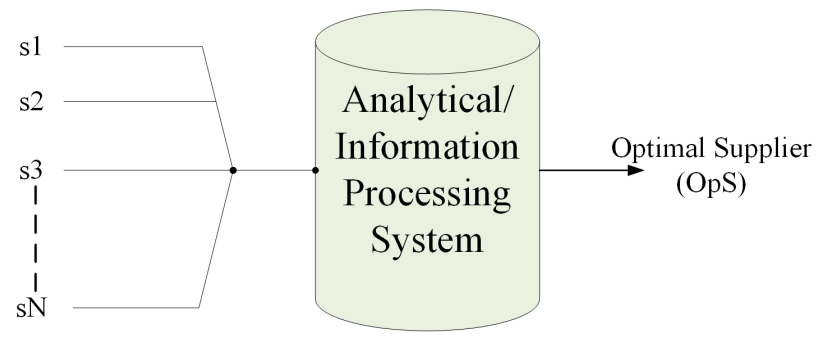

Figure 6: Effective Processing of all $N$ Supplier Data

\subsubsection{Effective Data Processing}

With is the acquired data, firms would be able implement machine learning algorithms to process, analyze, narrow down and select optimal supplier that deliver product that meets the defined requirement In simple term, OPTIMAL SUPPLIER (OpS) means suppliers who can supply be able to supply the correct materials with the best price and the right quality that adheres to all defined constraints.Use of technology in the procurement process will ensure quick flow information with the supplier which in turn ensure and results in high productivity since many human factors or errors would be eliminated.

Strategic procurement with information system before initiating negotiations will provide and compare the collection of supplier data monitored to ensure that supplier complies and adhere to all the well-defined corporate policy. These policies include;

Process and design capabilities: Suppliers ought to have upto-date and capable merchandise, yet as method technologies to provide the fabric required. as a result of completely different producing and repair, processes have varied strengths and weaknesses, the shopping for the organization should remember those characteristics up front. One way to cut back the time needed to develop new merchandise is to use qualified suppliers that square measure able to perform product style activities.

Quality assurance and reliability: Quality levels of the procurement item may be a vital issue and influences provider choice. Product quality ought to be in line with the lay-down product needs since it will directly have an effect on the standard of the finished merchandise.

Cost: The unit cost of a product's material is not deemed the most important aspect of supplier selection, rather the total cost of ownership is considered as the crucial factor. The total cost of product ownership includes the material unit price, the agreed payment terms, the cash discount, the cost of ordering, the cost of transportation or shipment, all logistical costs, projected maintenance costs, and many more qualitative costs that may not be easily assessed.

Service: providers should be in a state to back up their goods by providing the best services to their clients when requested. Buying firms always need to evaluate after purchase service incentives awarded by potential suppliers. This is very important especially when the buying firms have enough expertise concerning the product maintenance.

Capacity and geographical location: The buying organization needs to consider whether a potential supplier has the capacity to fill orders to meet all defined requirements and the ability to fill large orders if needed. Geographical location is another important factor in supplier selection because it inevitably has a huge impacts delivery lead time, transportation, and other logistical costs.

Factors to consider also include; system planning and control, firm's management capability, financial commitment and cost structure, longer-term relationship potential. The implementation of smart [T] systems build for effective negotiation and supplier selection process would aid purchasing firms leverages all available negotiation best strategies and practices to achieve bottom-line or optimal results [19]. [T] assist in inconsistent monitoring of supplier progress. Using IT gives the firms access to embedded social collaboration makes easy to harness and combine team effort to create 
more appropriate and effective negotiation documents. Firms the uses IT in procurement process mostly have access to well-proven analysis tools that allow the?firm to quickly evaluate supplier bids based on predetermined factors - such as price, quality, and value allowing the firm to arrive at the best possible award based on your unique business requirements.

\subsection{Approval/award contract}

The supplier that has been selected to provide the product will then be awarded the contract that carefully is having the conditions and terms that will be agreed by two parties. The fixed prices and the cost of the services will reflect on the contract. The organizations are expected to use the product requirements for the selection process. The approved supplier has the mandate to deliver their products as stipulated in the agreement of the contract. Reliability and efficiency are the core elements of the supplier.

\subsection{Supply chain management process}

This is another part of the purchasing process that links all the necessary information to other systems to enable both buying and capturing of what is needed. Information is always flowing bidirectionally between the supplier and the customer in Figure 7

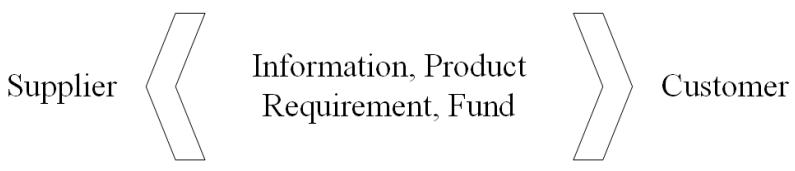

Figure 7: Supply chain fund management flow chart

Supply management has other activities that enhance the purchasing process, that can be breaking down into the supply chain macro process as shown in the Figure 7. The customer's relationship management system is there to capture and manages the details about what is available on the market, the prices, the selling of the products, creating a route for the firm to get updates on what is available. This guides the majority of firms to practice strategic planning and fulfill the demand and supply. The Figure 8 indicates the link in the supply chain macro process.

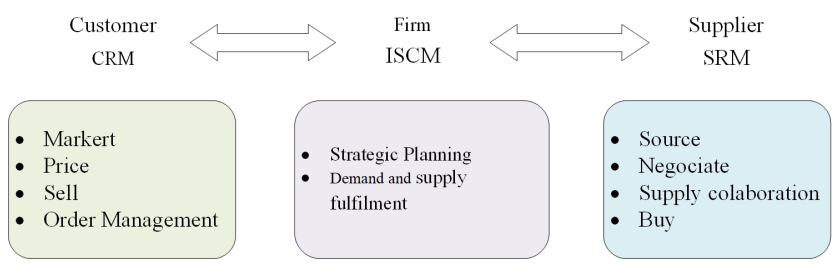

Figure 8: supply chain macro process

\subsection{Product delivery, payment review, and process eval- uation}

\subsubsection{Product delivery and payment}

The other stage of purchasing is product delivery, this stage collects and compiles the information that is needed for arrangements of how the product will be delivered to the specific firm or an individual. In Order to survive in the industry and gain competitive advantages, improvements such as reducing inventory and dependable delivery must be made, the introduction of data exchange systems that facilitates and communicate demand to suppliers and production progress data to customers within the network [14].

The products are stored to be delivered either in the warehouse or to individuals. Information technology system used in capturing the details in forms, others can be labeled electronically. Payment of the products is processed immediately after selecting the product and placing the order of it.

\subsubsection{Process evaluation}

After payment and delivery of the product, the systems are reviewed to map a way of eliminating errors and shortfall that occurred during the interaction of the purchasing process. At this stage, crucial decisions about changing the suppliers can be made based on the outcome of the services provided by the previous supplier. Recommendation and amends are drawn for future processing.

\section{Key Elements of Enterprise Resource Planning, Purchasing Databases, and Electronic Communication Systems}

The business market is constantly revolving and enterprises must revolve with it in order the maintain the necessary market presence. As firms hierarchy decides to invest in ERP system, they must ensure that the targeted system functionalities aligns with the overall firm's goal. This section will sort to elaborate on information system for procurement, crucial factors to consider when an enterprise is planning on purchasing and information system.

\subsection{Enterprise Information System Purchasing}

Business information systems are generally termed as ERP(Enterprise Resourcing Planning) system. It is a software package largely used by firms to effectively manage and handle day-to-day business activities or transaction, activities such as accounting, procurement, project management, risk management and compliance, and supply chain operations.

A complete ERP suite as an enterprise performance management software package helps firms to arrange, budget, predict, associate degree report on an organization's monetary results. Basically the key elements in the ERP include; One centralised location either onsite or cloud-based, Integrated Reporting Analytics, Efficient Data Import and Data Handling, Customer Relationship Management, Materials Requirement Planning, Materials Management, Engineering Change Order, Recall Management and Tracking, Production Planning \& Execution, Document and workflow management, Mobile ERP and Automation. 


\subsection{ERP System Evolution}

The implementation ERP systems by the firm and can be dated back the mid of 20th-century various departments within many organizations begun to use to function independently and these departments are often referred as functional silos [22]. The building blocks of ERP system basically comes from manufacturing resource planning systems (MRP] [23]. Inevitably, those systems were ineffective because they were deprived of many benefits of integrative coordination. It brought a huge financial burden on the firm because most of the systems at the time were not reusable since it needs massive rework and designs needs to be overhauled when the product was completely manufactured. A Framework of MRP is shown in Figure 9

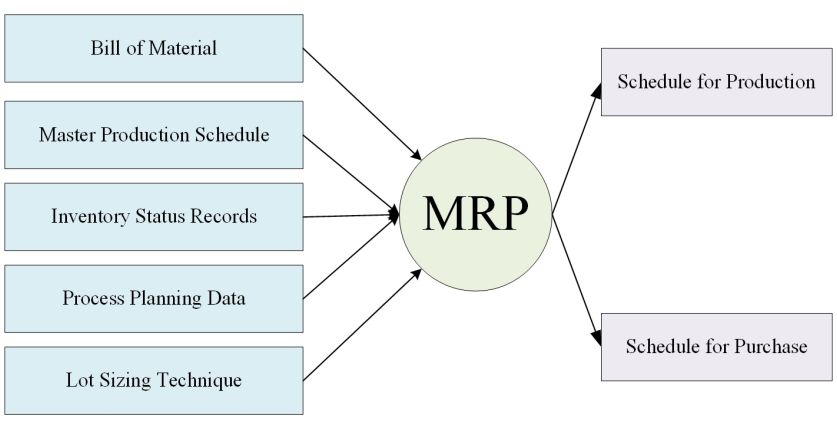

Figure 9: Framework MRP Software 22]

In the subsequent decade, MRP systems were evolved. Material Requirement planning is the software architecture that facilitates material requirement and planning as in Figure 9[22]. It receives the following user input:

- Bill of material stating details of the materials, components, and sub-assemblies needed to form every product.

- Master Production Schedule. Once the quantities are needed to satisfy demand.

- Shelf life: that is period of keeping materials.

- Inventory status records such as Manufacturing lead time data, Purchase lead time data

- Process Planning Data. This includes a whole range of data required for process planning like routings, process plans, quality testing methods, labour standards, machine standards

This MRP software generates the following output [22]:

- Details report about the product to be produced and production timeline. That involves everything from start to finish each stage is in the process is monitored. It also allows quantities and generates necessary reports.

- Detail report for the schedule of purchase. material to be purchased and date on which purchase must be made both questions are answered here.

Above MRP programs were not flexible enough if something goes wrong, like break down of machines or delay in delivery of purchased items. This eventually created inconveniences for users.
In 1990, Gartner created the term ERP to explain the evolution of material requirement planning (MRP) and manufacturing resource planning (MRPII) because of the need expanded beyond manufacturing into other integral parts of the enterprise, typically finance and HR [24-26].

The ERP system implementation began in the 1990s until somewhere the start of the 21 st century where the usage system grew exponentially. Later it absolutely was discovered that the prices of implementing ERP system began to rise. The hardware needed to run the software package was usually on-site, with massive machines in a very server area. The capital is required to purchase hardware and software licenses. In addition, nearly all organizations always prefer to customize their ERP systems to fit their specific needs instead of default settings and packages that come with the software and this also generates an additional expense of software consultants and training.

As technology grew up and limits of business crossed regional barriers want for tightly integrated programs which may seamlessly integrate all aspects of business in real time manner was necessary. This was extremely since it does not only to integrate all functionalities in one unit of a firm but also to integrate and unifies different parts of firms having a national or global presence. The modern ERP systems find ways to take handle these issues since they could $\mathrm{b}$ joint with the old systems. Though the transition from the legacy system to the modern system was involved with a lot of challenges, firms were able to transit the same [27]. with this, information was available to a specific user at the right time with the right permission to a specific user in a real-time environment. Availability of real-time data across each functional modulation with simulation capabilities were some of the important characteristics of these systems.

The rapid growth of the use internet made it easy for ERP to expand in the business section, such as the customer relationship management CRM, human capital management (HCM), supplier relationship management SRM, supply chain management SCM, inventory management, accounting, business intelligence and ecommerce and this exponential enabled firms to increase performance in marketing [28-30].

\section{Future requirements of electronic pur- chasing systems that will enable infor- mation visibility}

This section address the necessary future requirement or features to sort when purchasing an ERP system. The advantages and disadvantages of ERP system is fully discussed. Recommended solutions are for the possible disadvantages are presented. Further more, a short list ERP software packages are presented according the firm size. 


\subsection{Cloud Integrated ERP System}

The growth of knowledge in ICT has significantly influenced all sides of computing applications across organizations. Additionally, the business setting is changing into more and more complicated with useful units requiring additional and more inter-functional information flow for higher cognitive process, timely and economical acquisition of product components, management of inventory, accounting, human resources and distribution of products and services.

Meanwhile, the continuous evolution of ERP technology has completely embraced the internet, with new options and practicality, like embedded analytics has been added. Many firms are quickly migrating to cloud-based ERP system from on-site ERP because firms have discovered the difficulty in maintaining and keeping up with the trend of security demands or rising technologies, like smartphones whiles using on-site ERP systems. Currently, cloud computing has effectively released firms form overly burdening themselves with ERP security demand, the maintenance cost of the on-site ERP system. Usage of cloud-based ERP system, has for example, improve inventory management capabilities for enclosed technology like barcode scanning and storage or RFID tags; nowadays, the explosion and rapid development of the interconnected web of devices which is also known as Internet of Things [IoT] [31], has directly made cloud-based ERP even more attractive.

Also, the continued digital revolution and progressively cheap laptop process power has brought changes to nearly every space of business operations [32]. ERP systems have become a cloud-based hosted software technology [33]. In a cloud (server in a remote location), the users are granted access to a system by the respective or selected service provider, this includes full and complete access to hardware, and storage capacity, where system and hardware management are highly transparent to the users [34]. The major reason why firms moved to ERP system is typical to reduce costs, improve overall decision making through better reporting generated by provided capabilities, improve customer-supplier relationships, meet market and legal requirements, and to increase process efficiency [35]. With a cloud-based ERP system, firms have access to the ERP system that is hosted at a chosen service provider's site via the Internet. In addition, the responsibility regarding updates, managing servers, maintenance, and performing backups lies with the service provider instead of the firm which inherently cuts cost [33, 36]. In other words, the cloud ERP service providers ensure that maximum security, constant stability, and effortless operation of the system on behalf of its client users. Currently, cloud-based ERP systems have gained increased attention and investment from all around the globe.

Since the emergence of cloud-based ERP systems, the large ERP system implementations are focused on the cloud [34]. Cloud service model gives the client the opportunity to have quick access to the on-demand network and to share a bundle of resources. These resources will embrace, servers, networks, storage, applications (e.g. ERP), and others [34] Software as a Service SaaS) technology is implemented as a delivery mode for cloud-based ERP system [37, 38]. SaaS eliminates the requirement to physically install and run the server-side applications on the customer own premises, and eliminates the requirement for back-end hardware and data-centers needed to run the system [27], that successively simplifies the application's maintenance and support operations. This makes it possible for small organizations to take advantage of ERP systems, as they require neither the substantial resources nor the skills needed for successful on-premises implementation [32, 33].

\subsection{Advantages and Disadvantages of ERP System}

The ERP system comes numerous benefits that cannot be realized in firms that still use traditional purchase process. The positive impact of modern ERP system significantly out weights the negatives, it does comes with its related opportunities and challenges as described in [39]. The advantages and disadvantages are presented in the Table 2 and Table 3 respectively.

Table 2: Advantages of Cloud-Based ERP System

\begin{tabular}{|l|l|}
\hline Advantages & Aspects \\
\hline $\begin{array}{l}\text { Reliable and easy } \\
\text { information avail- } \\
\text { ability }\end{array}$ & $\begin{array}{l}\text { Common DBMS permits and allows consistent, accurate } \\
\text { data and improved reports. }\end{array}$ \\
\hline $\begin{array}{l}\text { Redundancy miti- } \\
\text { gation for data and } \\
\text { operations }\end{array}$ & $\begin{array}{l}\text { Modules access the same data through a centralized } \\
\text { database, and this helps avoids and remove multiple in- } \\
\text { puts and update operations. }\end{array}$ \\
\hline $\begin{array}{l}\text { Less delivery and } \\
\text { low cycle time }\end{array}$ & Minimizes data retrieval and reporting delays. \\
\hline Cost-effective & $\begin{array}{l}\text { Time savings are achieved due to improved control by } \\
\text { firm-wide analysis of all purchase decisions making pro- } \\
\text { cesses. }\end{array}$ \\
\hline Easy adaptability & $\begin{array}{l}\text { Relay for information about changes in current business } \\
\text { processes is easy and swift to adapt and restructure. }\end{array}$ \\
\hline $\begin{array}{l}\text { Improved scalabil- } \\
\text { ity }\end{array}$ & Availability of structured and modular add-ons. \\
\hline $\begin{array}{l}\text { Improved mainte- } \\
\text { nance }\end{array}$ & $\begin{array}{l}\text { Vendor provides long-term supports as part of system } \\
\text { procurement. }\end{array}$ \\
\hline Global outreach & Availability of module extension like CRM, SCM, etc. \\
\hline $\begin{array}{l}\text { E-Commerce and } \\
\text { e-business }\end{array}$ & Excellent Internet commerce, collaborative culture. \\
\hline
\end{tabular}

Table 3: Disadvantages of Cloud-Based ERP System

\begin{tabular}{|c|c|}
\hline Disadvantages & Suggested Solution \\
\hline Time-consuming & $\begin{array}{l}\text { Sensitive issues minimization, reduce internal politics and } \\
\text { call for general consensus }\end{array}$ \\
\hline Expensive & $\begin{array}{l}\text { Cost varies from thousands to millions of funds. Re- } \\
\text { engineering existing business process could be extremely } \\
\text { high. }\end{array}$ \\
\hline $\begin{array}{l}\text { Modules confor- } \\
\text { mity }\end{array}$ & $\begin{array}{l}\text { Architecture and related system components should } \\
\text { match to current business processes, culture as well as } \\
\text { strategic goals of the firm. }\end{array}$ \\
\hline depen- & $\begin{array}{l}\text { Multi-vendor vs. single-vendor consideration and long- } \\
\text { term support commitment. }\end{array}$ \\
\hline $\begin{array}{l}\text { Features and com- } \\
\text { plexity }\end{array}$ & $\begin{array}{l}\text { ERP system is packed many modules so firms must do } \\
\text { careful consideration and implement only the needful. }\end{array}$ \\
\hline $\begin{array}{l}\text { Scalability and } \\
\text { global presence }\end{array}$ & $\begin{array}{l}\text { Look for vendors with long-term product and services } \\
\text { commitment, Internet-enabled systems and global invest- } \\
\text { ment. }\end{array}$ \\
\hline $\begin{array}{l}\text { ERP capability ex- } \\
\text { tention }\end{array}$ & 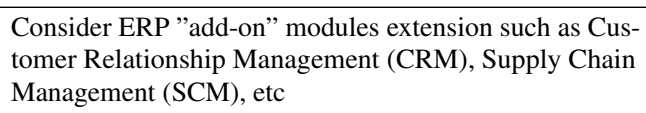 \\
\hline
\end{tabular}




\subsection{On-Premise ERP versus Cloud-Based ERP}

Firms operate on-premise or on-site ERP system is responsible to updating and maintaining their system and keeping it up-to-date, this firms also need to undertake extensive user re-training efforts to correspond with the system upgrade [40]. The cloud-based ERP updates, testing is undertaken by the services provider or vendor. This significantly reduces the burden and unnecessary delay in the overall project actualization. Therefore, if the vendor has thoroughly conducted tests prior to an update, the client organizations would largely be shielded from these any negative effects experienced by the on-site ERP users [41]. Updating a cloud-based ERP system is provided below:Firms operate on-site ERP system is fully responsible in updating, their system maintenance and keeping it up-to-date, this firms also need to engage in extensive user re-training program in an efforts to successfully push new system upgrade [40]. While cloud-based ERP platform or system update and testing are facilitated and undertaken by the services provider or vendor. This significantly reduces the effect of any unnecessary project delay. Typically, vendors conduct enough tests prior to any new update to ensure that new functionalities integrate seamlessly and this largely shields client organizations from any negative effects experienced by the on-site ERP users due to pushed updates] [41]. Cloud-based ERP is equipped with the following benefits:

- It is easier to introduce and use a new functionality introduced by vendors [34];

- Less planning, testing, maintenance, and configurations from the customer's side since everything is fully automated by the vendor [33, 34];

- Lower costs, both with maintenance and IT staff, and updates are free of costs [33, 34, 37];

- The vendor has the possibility to expand its potential customer base, and let the users focus on their core competencies [34,37];

- It is the vendor who provides a help-desk and maintenance support [42];

- The firms are not the owners of the system, as they do not own the infrastructure or run the applications and thereby not responsible for maintenance [43];

- Cloud-based ERP vendors regularly release new versions [41];

- Cloud-based ERP systems usually get frequent updates and new functionalities as compared on-site ERP systems [34].

As stipulated above, the main advantages of cloud-based ERP are that updates are free. There are enough good reasons why the vendor should invest time and resources in updating the system, even when it is free for users as technology updates are an inescapable process with dealing with any man-made creation utilized for productive gain [40]. A frequent update is done by vendors: ERP system to allow their customer firms to constantly evolve and optimize their business processes, and improve decision-making [40].

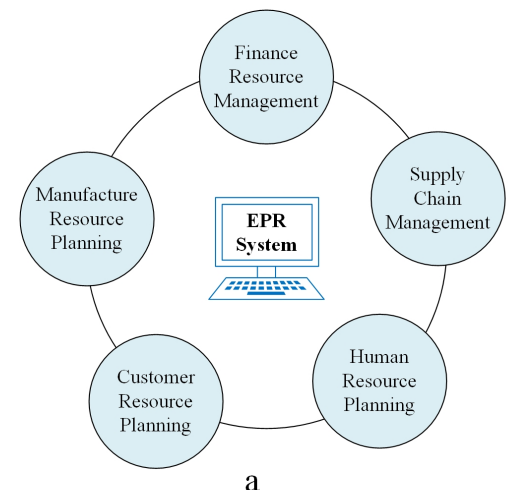

a

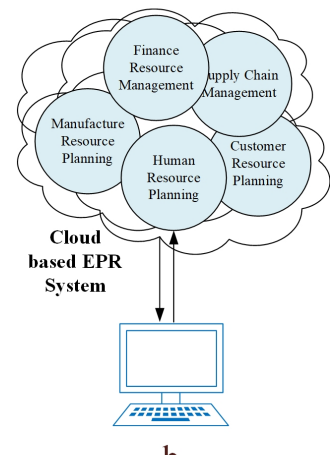

b
Figure 10: On-Site ERP versus Cloud-Based ERP System

The Figure 10 (a) shows an on-site ERP system which can only be accessed when on-site. Figure 10 (b) shows a cloud-based ERP system that demonstrates the evolving technologies and how efficient it is to managing purchasing and supply chain within organizations.

\subsection{Available Cloud-Based ERP System}

Purchasing ERP system is greatly dependent on firm size. Therefore, careful and objective decision must be made by firms that are considering purchasing ERP system. Selecting the correct and best ERP system for any firm operation can prove very challenging. this because many parameters are considered such as precision, flexibility, technologically integral. Supply chains are revolving at a very fast pace. With many production facilities and related suppliers gravitating more toward technologically-oriented method of doing business. Embracing cloud-based ERP systems definitely comes with positive impacts

Table 4: Suggested Cloud-Based ERP System to Company Size

\begin{tabular}{|l|l|l|}
\hline Enterprise & Medium-Sized & Small Business \\
\hline SAP & Netsuite & Deltek \\
Oracle & Sage & Work(etc) \\
Microsoft Dynamics & Infor & Syspro \\
IFS Applications & Macola & Intacct \\
\hline
\end{tabular}

The Table 4 presents a list few ERP System fits the three categories of business types. ERP software varies widely from one system to the other systems because different vendors have different market focus and thereby offer features that attract targeted markets.

However, most systems offer numerous modules: Human resources, CRM, Finance/Accounting, IT Helpdesk, e-commerce, Supply Chain Management, Order Processing, Inventory, and Procurement. However, most systems can provide many of those modules: Human resources, Finance/Accounting, IT service, ecommerce, provide Chain Management, Order process, and Inventory.

Additionally, department specific modules, several ERP platforms unit are specifically designed for specific industries like producing, field service, or technology. Industry-focused ERP systems package useful options along and should provide a helpful start line 
for those new ERP computer code. With ERP system customers will access any data at any time from anyplace victimization devices like a pill, smartphones.

\subsection{Factors to Consider When Purchasing (Cloud- Base) ERP System}

It is important for firms to migrate to an ERP system in order to remain relevant in the current market trend. Before migration firms must ensure that the preferred ERP system has the following features; It is important for firms to migrate to an ERP system in order to remain relevant in the current market trend. Before system migration firms must ensure that the preferred ERP system is fully equipped with the following features;

\subsubsection{Upgrade vs. Replacement}

Evaluate first if the firm needs to get a brand new ERP system or just an upgrade. Many current ERP is modularized and allows integration of new modules such as payroll with current applications. With this approached, the firm minimizes disruption and costs. With this also, a firm can leverage the cloud-based ERP for mobility, effective integration, increased scalability, deployment options, machine learning, and predictive analysis.

\subsubsection{Training and Setup}

On-premise ERP solutions need technical knowhow personnel to install but cloud-based ERP removes that barrier which in turn reduce cost. The installation often has charged independent from the cost of license but using SaaS or cloud-based ERP only requires an account activation to enable access all necessary service from the selected providers' server.

\subsubsection{Reporting and Dashboards}

Current ERP solutions feature an advanced reporting interface that can generate complete financial statements depending on the configuration. Check available tools such as reporting tools, in-system query, smart filters, and real-time data visualization. Dashboards include functions such as quantitative vs. qualitative data at a user, role, and department levels.

\subsubsection{Integration}

Desired ERP should seamlessly work with your currently existing business applications; this is essential when firm want to upgrade their existing system. Firms should consider the following integration points; system-system (such as CRM, HRMS), module-system (ERP payroll with existing HRMS) and also have varieties of export/import capabilities (PDF, JPG, CSV extension). The selected ERP system should have flexible integration process in order to ensure safe and smooth records and files migration.

\subsubsection{Customization}

This depends on every firm's priorities and working culture. Therefore, firms research and for an ERP System with customization tools such as departmental dashboard localization, and configurable workflows, among others. This allows departments such as marketing, accounting, production, sales to effectively execute their define goals and organize the ERP environment based on their parameters.

\section{Conclusion}

In conclusion, the study defined as purchasing is acquiring goods to satisfy organizational needs, individuals or departments. The key roles of purchasing goods are buying the inputs competitive price and ensuring reliable and consistent flows of goods. The use of an information technology system in purchasing help enhanced the operation and process in an organization by eliminating errors.

The purchasing process has become more efficient because the vast volume of paperwork is now reduced and cross-checking of records from the supplier and the customer's product specifications. This process is underlined with sufficient procurement planning, strategic resource allocations, staff competency, and procurement procedures respectfully. Thus enabling the organization to utilize the information processing features that collect analyze and coordinate in order to establish productive operational, effective and strategic decisions [12]. Recent studies have based on effects associated with the use of $\overline{I S}$ in supply chains.

There is evidence of an upwards productivity for a well-planned with supply chain coordination and integration that is facilitated by the use of integrated information technologies [44]. The suggested way to promoting effective Purchasing Process for future requirements to use tools that enhances the online requisitions. The use of electronic data interchange and online ordering through electronic catalogs are the new technology routes that individuals and organizations use to purchase their products.

Therefore, the on-site ERP system is being fully replaced by the cloud-based ERP, because it utilizes up-to-date and available cutting-edge technology platforms to reach a vast number of users and business around.

Conflict of Interest The authors; Pearl Keitemoge and Daniel Tetteh Narh certify that they have NO affiliations with or involvement in any organization or entity with any financial interest (such as educational grants; participation in speakers' bureaus; membership, employment, consultancies, stock ownership, or other equity interest; and expert testimony or patent-licensing arrangements), or non-financial interest (such as personal or professional relationships, affiliations, knowledge or beliefs) in the subject matter or materials discussed in this manuscript.

Acknowledgment We are grateful for the opportunity that was granted to us, and to be able to share more insight on Effective Application of Information System for Purchase Process Optimization. Also grateful for the support that we receive from the family and friends, thank you. 


\section{References}

[1] W. D. Presutti, "Supply management and e-procurement: creating value added in the supply chain[J]," Industrial Marketing Management, 32(3), 219-226, 2003, https://doi.org/10.1016/S0019-8501(02)00265-1.

[2] M. Ben-Daya, E. Hassini, Z. Bahroun, "Internet of things and supply chain management: a literature review," International Journal of Production Research, 57(15-16), 4719-4742, 2019, https://doi.org/10.1080/00207543.2017.1402140.

[3] H. T. Y. C. Chang, H., C. H. Hsu, "E-procurement and supply chain performance[J]," Supply Chain Management An International Journal, 18(1), 34-51, 2013, https://doi.org/10.1108/13598541311293168.

[4] S. Qrunfleh, M. Tarafdar, "Supply chain information systems strategy: Impacts on supply chain performance and firm performance[J]," International Journal of Production Economics, 147(2), 340-350, 2014 https://doi.org/10.1016/j.ijpe.2012.09.018.

[5] D. Nelson, P. Moody, J. Stegner, “The purchasing machine,” New York:The Free Press;, 184, 2001.

[6] B. Hamza, A. Gerbi, S. H. Ali, Senait., "Factors Affecting Procurement Performance in the Case of Awassa Textile Share Company," Global Journal of Management And Business Research, 16(3G), 2017, https://www.journalofbusiness.org/index.php/GJMBR/article/view/2085.

[7] A. Barros, . D. P, C. Ishikiriyama, P. S., C. R., "Processes and Benefits of the Application of Information Technology in Supply Chain Management: An Analysis of the Literature[J]," Procedia Computer Science, 55, 698-705, 2015 , https://doi.org/10.1016/j.ijpe.2012.09.018.

[8] F. Sollish, J. Semanik, The procurement and supply managers' desk reference, Wiley \& Sons, USA New Jersey, 2nd edition, 2012.

[9] P. Triantafillou, "Benchmarking in the Public Sector: A Critical Conceptual Framework," Public Administration Journal, 8(4), 17-32, 2007, https://doi.org/10.1111/j.1467-9299.2007.00669.x.

[10] T. S. Mclaren, M. M. Head, Y. Yuan, "Supply chain management information systems capabilities. An exploratory study of electronics manufacturers," Information Systems and E-Business Management, 2(2-3), 207-222, 2004, https://doi.org/10.1007/s10257-004-0035-5.

[11] R. Shah, S. M. Goldstein, P. T. Ward, "Aligning supply chain management characteristics \& inter-organizational information system types: an exploratory study," IEEE Transactions on Engineering Management, 49(3), 282-292, 2002, https://doi.org/10.1109/TEM.2002.803382.

[12] S. Qrenfleh, M. Tarafdar, "Supply chain information systems strategy: Impacts on supply Chain performance and firm performance," international Production Economics, 147(2014), 340-350, 2012, https://doi.org/10.1016/j.ijpe.2012.09.018.

[13] N. E. W. T. Gunasekaran, A., "Information systems in supply chain integration and management," European Journal of Operational Research, 159(2), 269-295, 2004, https://doi.org/10.1016/j.ejor.2003.08.016.

[14] C. M. Madhusudhana, K. Prahlada, "Delivery Performance Management Supply Chain Management: case study in Batteries manufacturing firm," Serbian Journal of Management, 6(2), 205-220, 2011.

[15] R. Vera, P. ME., "An analysis of the supplier selection process," Omega International Journal of Management Science, 26(6), 739-750, 1998, https://doi.org/10.1016/S0305-0483(98)00023-1.

[16] S. K. Ruth M, "Factors Affecting the Selection of Optimal Suppliers in Procurement Management," International Journal of Humanities and Social Science, 2 14, 2012.

[17] S. Li, B. Ragu-Nathan, T. S. Ragu-Nathan, S. S. Rao, "The impact of supply chain management practices on competitive advantage and organizational performance," Omega, 34(2), 107-124, 2006, https://doi.org/10.1016/j.omega.2004.08.002.

[18] K. C. Tan, V. R. Kannan, R. B. Handfield, "Supply chain management: supplier performance and firm performance," International journal of purchasing and material management, 34(3), 2-9, 1998, https://digitalcommons.usu.edu/manage_facpub/278/.

[19] P. Baily, D. Farmer, B. Crocker, D. Jessop, D. Jones, Procurement Principles and Management, Prentice-Hall, Pearson Education Limited, England, 10th edition, 2008.
[20] L. L. Stanley, J. D. Wisner, "Service quality along the supply chain: implications for purchasing," Journal of operations management, 19(3), 287-306, 2001, https://doi.org/10.1016/S0272-6963(00)00052-8.

[21] S. E. Fawcett, G. M. Magnan, Achieving world-class supply chain alignment: benefits, barriers, and bridges, Center for Advanced Purchasing Studies Tempe, AZ, 2001.

[22] N. B. Patil, M. Samel, P. Tilak, D. Boban, "Evolution of Modern Enterprise Resource Planning (ERP) Systems on Technological Background," International Journal of Science and Research, 4(8), 2319-7064, 2015, https://www.ijsr.net/search_index_results_paperid.php?id=SUB157605.

[23] J. C. Wortmann, "Evolution of ERP Systems, Strategic Management of the Manufacturing Value Chain," The International Federation for Information Processing, 2, 1998, https://doi.org/10.1007/978-0-387-35321-0_2.

[24] Y. B. Moon, "Enterprise Resource Planning (ERP):a review of the literature," International Journal of Management and Enterprise Development, 4(3), 2007, https://doi.org/10.1504/IJMED.2007.012679.

[25] G. Group, “A Vision of Next Generation MRP II,” Scenario S-300-339, 4 1990.

[26] T. Beleţ, A. A. Purcărea, "The Evolution of Enterprise Resource Planning Systems Eng," International Journal of Advanced Engineering, Management and Science, 3-Issue-12, 2017, https://dx.doi.org/10.24001/ijaems.3.12.1.

[27] M. Armbrust, A. Fox, R. Griffith, A. Joseph, R. Katz, A. Konwinski, G. Lee, D. Patterson, A. Rabkin, "A view of cloud computing," Commun. ACM, 53, 50-58, 2010, http://doi.acm.org/10.1145/1721654.1721672.

[28] S. Sadagopan, The World of ERP in ERP: A Manegerial perspective, Tata Publishing Company Limited, McGraw-Hill, New Delhi, 1999.

[29] S. H. Chung, C. A. Snyder, "ERP Adoption:A Technological Evolution Approach," International Journal of Agile Management Systems, 2 (1)(2), 24-32, 2000, https://doi.org/10.1108/14654650010312570.

[30] C. Yen D. C., "A Synergic Analysis for Web-Based Enterprise Resource Planning Systems," Computer Standards and Interfaces, 24, 337-346, 2002, https://doi.org/10.1016/S0920-5489(01)00105-2.

[31] M. A. Vouk, "Cloud Computing Issues, Research and Implementations," Journal of Computing and Information Technology, 16, 235-246, 2008, https://doi.org/10.2498/cit.1001391.

[32] E. Bjelland, M. Haddara, "Evolution of ERP Systems in the Cloud: A Study on System Updates," Systems, 6, 2, 2018, https://doi.org/10.3390/systems6020022.

[33] M. Haddara, A. Fagerstrøm, B. Mæland, "Cloud Erp Systems Anatomy of Adoption Factors and Attitudes," journal Enterp Resour. Plan Stud, 22, 2015, https://doi.org/10.5171/2015.521212.

[34] J. Duan, P. Faker, A. Fesak, T. Stuart, "Benefits and drawbacks of cloud-based versus traditional ERP systems," Proceedings of the 2012-13 course on Advanced Resource Planning, 2013, https://www.academia.edu/2777755/Benefits_and_Drawbacks_of_Cloud Based_versus_Traditional_ERP_Systems.

[35] A. Elragal, M. Haddara, "The Future of ERP Systems: Look backward before moving forward," Procedia Technol, 5, 21-30, 2012, http://dx.doi.org/10.1016/j.fcij.2017.03.003.

[36] Z. Al-Mashari.M, "Supply chain re-engineering using enterprise resource planning (ERP) systems: an analysis of a SAP-R/3 implementation case," International Journal of Physical Distribution \& Logistics Management, 30(34), 296-313, 2000, https://doi.org/10.1108/09600030010326064

[37] G. Juell-Skielse, H. Enquist, Implications of ERP as Service in ReConceptualizing Enterprise Information Systems, Springer, Berlin, Germany, 2012, https://doi.org/10.1007/978-3-642-28827-2_10.

[38] G. F. H. Raihana, "Cloud ERP-A solution model," International Journal Computer Science Information Technology Security, 2, 76-79, 2012, iSSN: 22499555.

[39] M. A. Rashid, L. Hossain, J. D. Patrick, "The Evolution of ERP Systems: A Historical Perspective," in I. Global, editor, Enterprise Resource Planning: Global Opportunities and Challenges, 1-16, IGI Global, 2002, 10.4018/978-1931777-06-3.ch001.

[40] C. Calvert, P. B. Seddon, "The importance of ongoing ERP training and support,” AISeL, 91, 2006, https://aisel.aisnet.org/acis2006/91. 
[41] C. C. Claybaugh, K. Ramamurthy, W. D. Haseman, "Assimilation of enterprise technology upgrades: A factor-based study," Enterp Inf. System, 11, 250-283, 2017, http://DOI: 10.1080/17517575.2015.1041060;

[42] A. Elragal, M. Haddara, "The Future of ERP Systems: Look backward before moving forward," Procedia Technol, 5, 21-30, 2012, https://doi:10.1016/j.protcy.2012.09.003.
[43] R. Seethamraju, "Adoption of software as a service (SaaS) enterprise resource planning (ERP) systems in small and medium-sized enterprises (SMEs)," Inf Syst. Front, 17, 475-492, 2015, https://DOI 10.1007/s10796-014-9506-5.

[44] S. K. Vickery, J. Jayaram, C. Droge, R. Calantone, "The effects of an integrative supply chain strategy on customer service and financial performance: and analysis of direct versus indirect relationships," Journal of Operations Management, 21(5), 523-C539, 2003. 